\title{
Application of digital volume correlation to study the efficacy of prophylactic vertebral augmentation
}

\author{
Valentina Danesi ${ }^{\text {a }}$, Gianluca Tozzi ${ }^{\mathrm{b}^{*}}$, Luca Cristofolini ${ }^{\mathrm{a}}$ \\ ${ }^{a}$ Department of Industrial Engineering, \\ Alma Mater Studiorum - Università di Bologna, Italy \\ ${ }^{\mathrm{b}}$ School of Engineering, University of Portsmouth, UK
}

Submitted to: Clinical Biomechanics (CLBI-D-16-00234)

$\begin{array}{ll}\text { Version.0: } & 24^{\text {th }} \text { April } 2016 \\ \text { Version.1: } & 27^{\text {th }} \text { June } 2016 \\ \text { Version.2: } & 21^{\text {st }} \text { July } 2016\end{array}$

Statistics:

Word count (manuscript): 4804 (Introduction through acknowledgements, excluding references, captions and tables)

Word count (abstract): $\quad 248$

Figures: 9

Tables: 2

References: $\quad 80$

Address for correspondence:

Dr Gianluca Tozzi

School of Engineering

Anglesea Building, Anglesea Road

Portsmouth

PO1 3DJ

United Kingdom

Email:gianluca.tozzi@port.ac.uk 


\section{ABSTRACT}

2 Background - Prophylactic augmentation is meant to reinforce the vertebral body, but in 3 some cases it is suspected to actually weaken it. Past studies only investigated structural 4 failure and the surface strain distribution. To elucidate the failure mechanism of the augmented vertebra, more information is needed about the internal strain distribution. This study aims to measure, for the first time, the full-field three-dimensional strain distribution inside augmented vertebrae in the elastic regime and to failure.

8 Methods - Eight porcine vertebrae were prophylactically-augmented using two augmentation materials. They were scanned with a micro-computed tomography scanner (38.8micrometer voxel resolution) while undeformed, and loaded at 5\%,10\%, 15\% compression. Internal

11 strains (axial, antero-posterior and lateral-lateral components) were computed using digital 12 volume correlation.

13 Findings - For both augmentation materials, the highest strains were measured in the regions 14 adjacent to the injected cement mass, whereas the cement-interdigitated-bone was less 15 strained. While this was already visible in the elastic regime $(5 \%)$, it was a predictor of the 16 localization of failure, which became visible at higher degrees of compression (10\% and $1715 \%$ ), when failure propagated across the trabecular bone. Localization of high strains and 18 failure was consistent between specimens, but different between the cement types.

19 Interpretation - This study indicated the potential of digital volume correlation in measuring 20 the internal strain (elastic regime) and failure in augmented vertebrae. While the cement21 interdigitated region becomes stiffer (less strained), the adjacent non-augmented trabecular bone is affected by the stress concentration induced by the cement mass. This approach can help establish better criteria to improve vertebroplasty.

\section{Keywords:}

25 Prophylactic vertebral augmentation; Digital volume correlation; Cement-bone interface; 


\section{INTRODUCTION}

29 Vertebral fractures are a severe cause of morbidity and disability (Ferrar et al., 2005;

30 Tancioni et al., 2011), as well as a significant burden for healthcare systems (Goldstein et al., 2015). The cause of the fracture may be pathological, traumatic, or a combination of the two. The main pathological conditions are osteoporosis (WHO, 2007) and metastatic lesions (Sutcliffe et al., 2013), which are associated with metabolic alterations resulting in bone weakening. However, the biomechanics underlying fracture onset and development of postfracture and prophylactic treatments raises research questions that are still far from being answered.

Recently, prophylactic augmentation (cement injection in a non-fractured vertebra) has been proposed as an alternative to pharmacological treatments (Diamond et al., 2003) to reduce the fracture risk of osteoporotic vertebrae (Chiang et al., 2009; Kayanja et al., 2005; Langdon et al., 2009; Sun and Liebschner, 2004; Tancioni et al., 2011), or to prevent adjacent fractures after augmentation (Aquarius et al., 2014; Kobayashi et al., 2009). This treatment is meant to increase the strength and the structural support of weak vertebrae, by the injection of an augmentation material into the vertebral body (Aquarius et al., 2014; Chiang et al., 2009; Cristofolini et al., 2016; Oakland et al., 2008; Oakland et al., 2009; Sun and Liebschner, 2004).

Questions have been raised about the efficacy and safety of vertebroplasty in general, because of the associated risks such as cement leakage and subsequent neural damage; tissue necrosis due to residual monomer and to the exothermal reaction; increased risk of fracture in the adjacent vertebrae (Berlemann et al., 2002; Carrodeguas et al., 2004; Lewis, 2006; Tanigawa et al., 2006; Uppin et al., 2003). Prophylactic augmentation exposes the patients to such risks; hence there is a need for a clearer understanding on the cost-benefit trade-off. For this reason, in-depth knowledge of the mechanical behaviour and failure of augmented vertebra is of fundamental importance to understand vertebral biomechanics and improve diagnosis and prophylactic treatments (Oakland et al., 2008).

Furthermore, it is still debated whether prophylactic augmentation actually strengthens the treated vertebra. The increasing interest in the use of prophylactic augmentation, as a treatment for reduce the risk of fracture, has led to a number of experimental studies (Belkoff et al., 2001; Cristofolini et al., 2016; Heini et al., 2001; Ikeuchi et al., 2001; Kolb et al., 2013; 
2015; Steens et al., 2007; Tohmeh et al., 1999; Wilke et al., 2006). Several in vitro studies showed that the strength of augmented vertebrae was on average greater than that of nonaugmented vertebrae (Ikeuchi et al., 2001; Lim et al., 2002). However, there were also cases where single treated specimens were weaker than the untraded controls (Berlemann et al., 2002; Dean et al., 2000). In fact, augmentation has been found to strengthen (Bai et al., 1999; Higgins et al., 2003; Lim et al., 2002), to provide no improvement (Kayanja et al., 2005), or even to weaken at least some specimens (Berlemann et al., 2002; Widmer Soyka et al., 2016), in comparison to untreated controls. It must be noted that most of these studies focused on the overall failure strength of the natural and treated vertebral body, without analyzing the strain distribution.

The strain distribution has been partially assessed in the untreated vertebral body (Kayanja et al., 2004) (the most stressed region could not be identified as only one strain-gauge was applied on each vertebra). Recently, the strain distribution was measured for a variety of loading conditions with a large number (8) of strain gauges (Cristofolini et al., 2013). While strain gauges provide point-wise measurements, digital image correlation (DIC) allows for the investigation of full-field strain distribution on the surface of the specimen. In recent years, DIC has been successfully exploited to measure the strain distribution on the surface of untreated vertebrae (Campos-Lopez et al., 2015; Giambini, 2013; Grassi and Isaksson, 2015; Palanca et al., 2015a; Palanca et al., 2016). The surface strain distribution was also measured in augmented vertebrae in vitro, using 8 strain gauges (Cristofolini et al., 2016). The measured principal strains were generally aligned as expected: axially/circumferentially for all loading conditions, implying an axial force. It has been shown both experimentally (Cristofolini et al., 2016) and numerically (Widmer Soyka et al., 2016) that the variability of the weakening/strengthening effect depends on the quality of augmentation (amount, localization and distribution of the injected material). Even that study could not draw any conclusive information about the failure mechanisms associated to the internal state of the vertebra.

Numerical predictions through finite element (FE) models allowed the investigation of the internal strain distribution (e.g. (Kinzl et al., 2013; Sun and Liebschner, 2004; Wilcox, 2006)). However, FE models of complex structures such as an augmented vertebra, which include a thin cortical shell, cement-bone interdigitation, tissue anisotropy, inhomogeneity and nonlinearity must be first verified and then validated (Cristofolini et al., 2010; Henninger et al., 2010). 
With the recent and rapid progress of high-resolution micro-CT imaging in conjunction with in situ mechanical testing (Buffière et al., 2010; Nazarian and Muller, 2004), digital volume correlation (DVC) emerged as a novel tool for the measurement of 3D deformation fields throughout entire bone volumes (Freddi et al., 2015; Roberts et al., 2014). So far, DVC has been successfully employed to examine full-field internal deformations in trabecular bone (Bay et al., 1999; Brémand F., 2008; Dall'Ara et al., 2014; Gillard et al., 2014; Liu and Morgan, 2007; Zauel et al., 2006), cortical bone (Christen et al., 2012; Dall'Ara et al., 2014; Palanca et al., 2015b) and cement-bone interface (Tozzi et al., 2014). Application of DVC to whole untreated vertebra was also exploited to examine yield and post-yield deformations (Hussein et al., 2012; Hussein et al., 2013). DVC is an ideal tool to investigate the internal mechanism leading to failure onset and progression in augmented vertebrae, and could potentially be used to elucidate under which conditions augmentation can reinforce/weaken the vertebral body.

While DVC has been applied to characterize the mechanical performance of untreated vertebral body, so far it has not been applied to augmented vertebral bodies. Recently, for the first time, 3D zero-strain studies demonstrated the suitability of DVC to investigate augmented vertebrae both at organ and tissue level (Tozzi et al., 2015). This study reported that strain uncertainties can be reduced below 300 microstrain if the images are adequately prepared (excluding the non-tissue background), and with an appropriate choice of the computation sub-volume size (i.e. 48 voxels for a 39 micrometers voxel size image).

The aim of this study was to use DVC, for the fist time, to improve the understanding of the failure mechanism inside prophylactically-augmented vertebral bodies. DVC was applied to measure the full-field strain distribution under compression inside the vertebral body augmented with two different cements. The approach enabled focusing on the injected cement, and on the cement-bone interdigitated region, in the immediate post-operative period. The investigation included both the elastic regime (axial, antero-posterior and lateral-lateral components of strain) and the yield/failure internal micro-damage mechanism.

\section{2. METHODS}

\subsection{Specimens and prophylactic augmentation}

122 Four porcine thoracic spine segments (T1-T3) were obtained from animals sacrificed for

123 alimentary purposes. The animals were all female, of the same breed, approximately 9 
124 months old and $100 \mathrm{~kg}$ at sacrifice. The single vertebrae were dissected, removing the soft 125 tissues, including the intervertebral discs (Fig.1). The vertebral bodies measured 20.0-24.0 $126 \mathrm{~mm}$ in the cranial-caudal, $18.0-20.5 \mathrm{~mm}$ in the antero-posterior, and $26.1-31.3 \mathrm{~mm}$ in the lateral-lateral direction. They were treated with two vertebral augmentation materials:

- Four vertebrae (Mendec-1, Mendec-2, Mendec-3, Mendec-4) were prophylacticallyaugmented with an acrylic cement (Mendec-Spine, Tecres, Verona Italy). MendecSpine contains $20.4 \% \mathrm{BaSO}_{4}$ pellets with an average size of 300 micrometers, which grant adequate visibility during micro-CT imaging (Tozzi et al., 2015).

- Four vertebrae (Calcemex-1, Calcemex-2, Calcemex-3, Calcemex-4) were treated with an acrylic-based cement (Calcemex-Spine, Tecres). Calcemex-Spine contains 26\% beta-tri-calcium-phosphate $(\beta-\mathrm{TCP})$, and $6.5 \% \mathrm{BaSO}_{4}$ pellets with an average size of 300 micrometers.

Augmentation was performed using a unilateral approach (Fig.1) using the proprietary mixing and delivery kit. Injection was stopped at the first visible sign of leakage (injected volume: $1.0-1.5 \mathrm{ml}$ of cement). In order to facilitate a more realistic flow and polymerization of the augmentation material, the vertebrae were placed in saline solution at $42^{\circ} \mathrm{C} 1$ hour before and 12 hours after augmentation (the physiologic temperature in pigs is $39-41^{\circ} \mathrm{C}$ (Reece, 2004; Ye et al., 2007).

The augmented specimens were tested within 60 days after augmentation. When not in use, the specimens were stored at $-28^{\circ} \mathrm{C}$ and sealed in plastic bags. Under these conditions the resorbable phase of Calcemex-Spine remains unmodified. In fact, this investigation aimed at replicating the post-operative conditions.

146 In addition, four vertebrae from those spines were tested in the natural condition (Natural-1,

147 Natural-2, Natural-3 and Natural-4): three of these specimens were part of a different study 148 (Tozzi et al., in press 2016). These specimens are included in the present paper for 149 comparison, as a blank control; more details about the natural specimens can be found in 150 (Tozzi et al., in press 2016).

151 Within each spine segment, two vertebrae were assigned for augmentation with two types of 152 bone cement, and one vertebra was used as the non-augmented control. Sampling was 153 arranged so that the augmented and control samples were well distributed within the spine 154 segment, in order to have at least one T1, one T2 and one T3 per group. 
155 The growth plates were removed from the augmented and natural vertebrae, together with the

156 adjacent endplates (due to the young age of the animals, this could be performed with little 157 manual effort), similar to (Hardisty et al., 2010; Tozzi et al., in press 2016; Tozzi et al., 158 2015). A reproducible reference frame was adapted (Danesi et al., 2014), and the ends of 159 each vertebra were potted in PMMA so that the cranio-caudal axis was consistently aligned 160 with the loading direction within the micro-CT scanner (Fig.1). The neural arches were 161 subsequently excised through resection of the pedicles.

\subsection{Compression testing and micro-CT scanning}

163 The augmented vertebrae underwent the same test protocol as the previous natural specimens 164 (Tozzi et al., in press 2016).

165 Destructive tests were carried out under axial-compression with a customized-micro166 mechanical loading device (CT5000, Deben Ltd, UK), equipped with a $5 \mathrm{kN}$ load cell and 167 environmental chamber filled with $0.9 \%$ saline solution (Fig.1). To avoid translation and 168 rotation of the specimens inside the chamber, a sandpaper disc was applied to the bottom 169 loading platen. The force and displacement signals were acquired at 2Hz (Microtest-V6170 2.67, Deben Ltd, UK).

171 A preload of $50 \mathrm{~N}$ was applied. Each specimen was subsequently compressed in 172 displacement control, in a step-wise fashion (Fig.1). At each step, the actuator moved by 5\% 173 of the specimen's free height (this corresponded to actuator steps ranging between 0.47 and $1740.67 \mathrm{~mm}$, depending on the specimen). It must be noted that such actuator displacement 175 included the actual bone compression, but also the compression of the PMMA pots, and the 176 compliance of the entire loading system. The actuator speed was $0.1 \mathrm{~mm} / \mathrm{sec}$. At each step, 177 the specimens were allowed to settle for 15 minutes, to reach a steady state prior to scanning. 178 Most of the relaxation (Fig. 2-3) occurred during such 15 minutes. Some additional 179 relaxation was unavoidable during imaging, but was one order of magnitude smaller than the 180 initial one (it never exceeded $10 \%$ of the initial force).

181 Micro-CT imaging (XTH225, Nikon Metrology, UK) was carried out at each step (0\% with $18250 \mathrm{~N}$ preload, 5\%, 10\% and 15\% compression, Fig.1). The micro-CT scanner was set to a 183 voltage of $88-89 \mathrm{kV}$, a current of $110-116$ microA and exposure time of 2 seconds. Images 184 were collected at rotational steps of $0.23^{\circ}$ over $360^{\circ}$, for a scanning time of approximately 90 
minutes at each compression step. The reconstructed micro-CT images had an isotropic voxel size of 38.8 micrometers.

\subsection{Digital volume correlation (DVC)}

188 The original micro-CT images were masked in correspondence to the contour, as regions with 189 no pattern (e.g. saline solution) are associated with large correlation artifacts (Tozzi et al., 190 2015).

191 DaVis DVC software (v8.3, LaVision, Germany) was used to investigate the full-field strains. 192 Briefly, DVC discretizes the 3D volume into sub-volumes, which are represented as a 193 discrete grey-level function (Freddi et al., 2015). To correlate the patterns in the undeformed 194 and deformed sub-volumes, a correlation function is applied. DaVis software deploys a 195 multi-pass approach that uses the displacements from the previous pass to deform the sub196 volume on the subsequent pass, until the highest possible correlation is achieved (Madi et al., 197 2013). In this application, a final sub-volume of 48 voxels ( $0 \%$ overlapping) was used, which 198 was reached through passes of $128,112,96,80$ and 64 voxels. This multi-pass sequence was found to produce the lowest strain error for such types of specimens and imaging settings

200 (Tozzi et al., 2015). The displacement and strain fields were calculated for each compression 201 step (i.e. matching subsequent images: 0\%-5\%; 5\%-10\%, 10\%-15\%). The steps were then summed in a Lagrangian coordinate system.

A Matlab (v2014a, MathWorks, US) script was developed to visualize the 2D strain maps in sagittal and frontal planes. Moreover, for each compression step, the average strain within each transverse slice was computed for the axial, antero-posterior and lateral-lateral components of strain (Palanca et al., 2016).

\section{3. RESULTS}

\subsection{Force-displacement curves}

209 An initial toe region could be observed in the force-displacement curves (Fig. 2-3). Its 210 extension was mainly dependent on the initial lack of co-planarity of the two pots.

211 For all the augmented specimens (Mendec-Spine, Fig. 2; Calcemex-Spine Fig. 3) the force 212 increased monotonically as compression was applied, until failure. Relaxation was also 213 visible at the end of each compression step, when the actuator was stopped to allow micro-CT 
214 imaging. Failure in most cases was clearly detectable as the point where force reached a 215 plateau or dropped. This occurred either during the third step (from 10\% to $15 \%$

216 compression: specimens Mendec-2 and Calcemex-1), or during the second step (from 5\% to $21710 \%$ compression: all other specimens. The force at $15 \%$ compression was on average lower 218 than the force at $10 \%$ compression (Table 1), confirming that the overall failure occurred 219 before the end of the test. Inter-specimen variability never exceeded 35\%; variability was 220 larger at $5 \%$ compression, compared to $10 \%$ and $15 \%$ compression.

221 Some augmented specimens (Mendec-1, Mendec-3, Calcemex-1, Calcemex-2) were stronger 222 than the respective controls (Tozzi et al., in press 2016), while others were weaker (Table 2).

\subsection{Qualitative inspection of micro-CT images: internal damage}

224 In all of the augmented specimens, the micro-CT images (Fig. 4-5) showed a main microdamage, which started to be visible at the $10 \%$ compressive step, and degenerated into a trabecular collapse at $15 \%$. For both cement types, the cement region appeared to be undamaged, even at the final loading stage (15\% compression), where failure tended to initiate in the trabecular bone adjacent to the cement-bone interdigitated region.

In the majority of the Mendec-Spine specimens (3 out of 4, Fig. 4) the main micro-damage was localized in the trabecular bone at the mid-height and at the same level of the cement mass. Such a collapse seemed to initiate from the cement-bone interface, then gradually spread across the trabecular bone anteriorly and finally reaching the cortical bone in the transverse plane. In addition, Mendec-1 showed additional micro-damage just below the cement region (Fig. 4, 15\% compression). Only for specimen Mendec-4 was collapse initiated at the two extremities (Fig. 4, 15\% compression), which ended with a trabecular crushing in most of the cranial and caudal regions, far away from the augmented region.

The specimens augmented with Calcemex-Spine showed a main micro-damage localized in the trabecular region just cranial or caudal to the cement mass (Fig. 5, 15\% compression). Only in Calcemex-2 the micro-damage was at the same height of the cement mass, towards the anterior of the specimen (Fig. 5, 15\% compression). Similarly to the Mendec-Spine specimens, such a collapse initiated from the cement-bone interface, and gradually developed across the trabecular bone anteriorly or posteriorly in the transverse plane, in some cases affecting the cortical bone (Calcemex-1 and Calcemex-2). 
244 In comparison with the control vertebrae (Tozzi et al., in press 2016) where failure initiated

245 unpredictably in different regions of the natural vertebral body, failure in the augmented ones 246 predictably initiated in the trabeculae adjacent to the cement mass.

\section{$247 \quad 3.3$ Internal strain distribution: elastic regime and failure}

248 As expected, the largest component of strain was the axial one, which was compressive (Fig. 249 6-7). The anterior-posterior and lateral-lateral components of strain (Supplementary 250 Material) were smaller in magnitude, and mainly tensile (Poisson effect).

251 At the first compression step (5\%) axial strains did not exceed -14000 microstrain, and localization of high-strain regions varied between specimens. Conversely, in the final loading step (15\%) the cement regions seemed to be less strained in all specimens, and the largest strains were generally observed adjacent to the cement-bone interdigitated region.

In the Mendec-Spine specimens, the highest strains observed at $10 \%$ and $15 \%$ compression (sometimes close to 90000 microstrain) were at the mid-height and at the same level of the cement mass (Fig. 6). Conversely, in the Calcemex-Spine specimens the largest strains (5060000 microstrain in most specimens; up to 110000 microstrain in Calcemex-2) were just cranial and caudal of the cement mass (Fig. 7). The highest strain was localized in a single region within the augmented vertebral body for most specimens; the only exceptions were Mendec-1 and Calcemex-4, where two distinct strain peaks were observed, adjacent to the cement mass. For the specimens augmented with both cement types, the regions of high strain (all components) seemed to match very well the localization of micro-damage visualized in the micro-CT images (Fig. 4-5). Strains were markedly lower away from the most stressed regions where damage initiated.

In comparison with the natural control vertebrae (Tozzi et al., in press 2016) the measured strain had the same order of magnitude. However, in the control vertebrae, the highest strain would unpredictably appear at any location inside the natural vertebral body.

The strain distribution in the augmented vertebrae in the elastic regime (5\% compression) seemed to predict the location of the micro-damage initiation before it actually became identifiable (at 10\% and 15\% compression) in most of the specimens (Fig. 6-7). Only the specimen Mendec-2 showed a relocation of the highest axial strain from the posterior (5\% compression, Fig. 6) to the anterior region (15\% compression). 
274 When the average axial strain was considered for each cross-section (Fig. 8-9), it was 275 possible to observe how the strain progressively increased for different steps of compression:

276 while at 5\% compression no section was, on average, more strained than the others, at $10 \%$ and $15 \%$ it became possible to detect which sections of each vertebra was more strained. The strain pattern along the caudal-cranial direction was mostly similar among the Mendec-Spine specimens, with the largest deformation localized in correspondence of the specimen midheight, or slightly displaced cranially as for Mendec-3 (Fig. 8). At 10\% compression the average axial strain in the most strained cross-sections were 3-5 times higher than in the less strained ones; such differences became even more pronounced at $15 \%$ compression. The trend found for the four Mendec-Spine specimens was different from the natural controls

284 (Tozzi et al., in press 2016), where the largest deformation was observed in correspondence of the cranial or caudal extremities. The strain pattern along the caudal-cranial direction of the four Calcemex-Spine specimens was different from the four Mendec-Spine specimens, but more similar to the natural controls (Tozzi et al., in press 2016) (Fig. 9).

\section{DISCUSSION}

The aim of this study was, for the first time, to measure the full-field internal strain distribution (all components of normal strain) by means of DVC in prophylacticallyaugmented vertebral bodies under compression. Specifically, we aimed to investigate the strain localization in the different regions of the augmented vertebral body (fully-augmented regions; cement-bone interdigitated regions; non-augmented bone tissue) with two different cements. We addressed both the strain distribution in the elastic regime, and failure initiation and propagation.

At a macroscopic level, similar forces were observed for the two types of cement. Our

297 findings showed that augmentation increased the force required to induce damage in some of 298 the vertebrae, compared to the natural controls. However, other augmented specimens (with 299 both cement types) had a failure force lower than the natural controls. These findings were 300 consistent with previous studies, which reported cases where prophylactically-augmented 301 vertebrae were weaker than the untreated controls (Berlemann et al., 2002; Cristofolini et al., 302 2016; Dean et al., 2000). This inter-specimen variability in the weakening/strengthening 303 effect (Table 2, Fig. 2-3) seems to confirm recent studies (Cristofolini et al., 2016; Widmer 304 Soyka et al., 2016), in which it has been hypothesized that the effect of augmentation depends 
on the quality of augmentation itself (i.e. amount, localization and distribution of the injected material).

307

308

309

310

311

312

313

Therefore, this study confirms the usefulness of DVC to investigate the internal strain distribution of augmented vertebrae, from the elastic regime up to failure. In fact, though a number of studies have used DVC to investigate the internal strain distribution of natural vertebrae under compression (Hardisty et al., 2012; Hussein et al., 2012; Hussein et al., 2013; Tozzi et al., in press 2016), the internal strain distribution of augmented vertebrae is still unexplored.

The results in this study clearly showed that prophylactic augmentation was not associated to an evident modification of the strain magnitude when compared to the control vertebrae, but rather to a different localization of the most strained regions, due to the cement distribution. Both the micro-CT images, and the DVC strain analysis highlighted that:

1. The cement mass was less strained than any other regions in the vertebra and never acted as strain concentrator for failure initiation. This can be explained by the additional stiffening and reinforcement associated with the infiltration of the cement inside the trabecular bone.

2. The highest strains and failure were localized in the bone adjacent to the cementbone interdigitated region. This can be explained by the strain concentration between two regions: the cement-interdigitated bone, which has become stiffer and stronger, and the adjacent non-augmented trabecular bone (where some trabeculae might also have been damaged by the injection process).

3. The strain maps in the elastic regime and the localization of failure was different in the augmented vertebrae, when compared to the natural controls. This suggests an alteration of the load sharing in the augmented structure where the load is mostly carried by the cement region, rather than the trabecular core in the vertebra.

4. The specimens augmented with the two cement types seemed to have different failure mechanisms. Both failure (Fig. 4) and the highest strains (Fig. 6) with Mendec-Spine were mainly localized at mid-height, and at the same level of the cement mass. With Calcemex-Spine, both failure (Fig. 5) and the highest strains (Fig. 7) were mainly cranial and caudal to the cement mass. To confirm such findings, a larger sample size would be required. 
337 The micro-CT images (Fig. 4-5) and the detailed DVC-computed strain maps (Fig. 6-7)

338 allowed identification of the most strained region (even when localized in small volumes),

339 already from the lowest degree of compression (5\%). Conversely, the average strain in each 340 cross-section (Fig. 8-9) allowed identification of the general trends, but not the single regions

341 of high strain, which are predictors of failure.

342 It must be noted that when a given displacement was assigned to the actuator (i.e. the travel 343 corresponding to $5 \%$ of the vertebral free height), this resulted in actual bone compression, 344 but also compression of the PMMA pots, and small deformations of the entire loading 345 system. Therefore, it is not possible to compare exactly the DVC-computed average 346 compressive strains with the theoretical value of the compression steps $(5 \%, 10 \%, 15 \%)$.

347 In summary: the most critical region was found at the boundary of the cement-bone 348 interdigitated region, where the onset of the fracture was recognizable, consistently with previous studies (Tozzi et al., 2012, 2014). Starting from the cement-bone interdigitated

350 region, the micro-damage gradually spread across the trabecular bone, which provided a 351 lower stiffness than the injected cement. In most of the cases, the micro-damage in the 352 trabecular bone was visible as compaction of the trabeculae, which is associated with bending 353 and buckling of trabeculae in the transverse plane (Tozzi et al., 2012).

354 It is known that augmentation in some cases weakens the vertebra compared to the untreated one (Berlemann et al., 2002; Dean et al., 2000). A recent study based on destructive testing and surface strain measurement (Cristofolini et al., 2016) suggested that such a weakening might be associated with the interaction of the cement mass with the host bone, if augmentation is sub-optimal. It has been shown (Cristofolini et al., 2016; Kinzl et al., 2012) that weakening tends to occur when the cement mass is far from the endplates, whereas

360 augmentation strengthens the vertebra when a cement bridge is formed between the 361 endplates. Our DVC investigation demonstrated, for the first time, that augmentation 362 reinforces the regions where cement is actually delivered (reduced strain), but localizes 363 higher strains at the boundary of the cement-interdigitated bone. If such a strain concentration occurs where the bone is strong (i.e. close to the endplates) this may not result in a critical weakening; conversely, if it occurs where the trabecular bone is weaker, this may facilitate failure. 
367 The perturbation of the internal strain distribution observed with the present DVC study 368 could explain the clinically-reported fracture in the vertebrae adjacent to the augmented one 369 (Grados et al., 2000; Han et al., 2009; Kim et al., 2004; Trout et al., 2006; Uppin et al., 2003).

370 There are some limitations in this study that must be considered. First of all, porcine specimens were used, which have a different anatomy and tissue properties than human tissues (Brandolini et al., 2014). The vertebral body heights of porcine T1 and T2 are equivalent to those of the human $\mathrm{T} 1$ and $\mathrm{T} 2$, while $\mathrm{T} 3$ is taller than the human $\mathrm{T} 3$; the endplate areas of porcine T1, T2 and T3 are 36\%-53\% smaller than the humans (Bozkus et al., 2005). In the current study it was necessary to use porcine specimens, because of the limited dimension and space available for the loading device inside the micro-CT-scanner. The bone mineral density of the porcine vertebrae is higher when compared to the human vertebrae (Aerssens et al., 1998). For this reason the amount of cement that could be injected in our specimens was significantly lower than the typical amount injected in humans.

380 Furthermore, despite their smaller size, the strength of the porcine vertebrae was of the same order of magnitude as the human ones. For this reason, the current results cannot be entirely indicative from a clinical perspective, as both the failure force and the strain magnitude may differ from human vertebrae. However, comparisons between natural and augmented specimens, and between different types of cement are possible. Furthermore, this study allowed, for the first time, a complete in vitro characterization of the internal failure mechanism in the augmented vertebral body.

387 Another limitation is the relatively small sample size: 4 specimens were tested for each 388 group, preventing any conclusive statistical comparisons. Larger samples $(\mathrm{n}=30-66)$ were 389 tested when only the failure force was measured (Furtado et al., 2007; Heini et al., 2001; Lim 390 et al., 2002). As in our study, where we investigated in detail the internal strain distribution, 391 a smaller number of specimens could be considered.

392 The inter-specimen differences in failure mechanism observed (e.g. Mendec-4 differed from 393 the other Mendec-Spine specimens) could either be caused by the different localization of the 394 cement mass (which unavoidably occurs as the cement flows inside the bone) or by suboptimal alignment of the pots at the extremities.

396 All these limitations are compensated by the fact that, to the author's knowledge, this is the 397 first time that the internal strain distribution (from elastic to post yield regime) through DVC 
398 was employed to investigate the internal failure mechanism in prophylactic-augmented 399 vertebrae.

\section{5. CONCLUSIONS}

401 In conclusion, this study has demonstrated the potential of digital volume correlation in 402 measuring the internal strain and failure in prophylactically-augmented vertebrae. It has been 403 shown that failure starts inside the augmented vertebral body, next to the injected cement 404 mass. This information (in terms of localization of the cement mass) can help improve 405 treatment protocols for vertebroplasty.

406 


\section{Acknowledgements}

408 The authors with to thank: Tecres (Verona, Italy) for donating the bone cements and 409 providing the injection kits; Renzo Soffiatti and Roberta Tosato for their advice about 410 injectable materials; Marco Palanca for the Matlab scripts and for his advice with DVC; 411 Remo Antelli for donating the porcine spines; Alessandra Danesi and Matteo Succi for the 412 medical images; Colin Lupton for the technical support in micro-CT; Dave Hollis for the 413 assistance with DVC software; Marco Curto for the technical support and Piers McEwan for 414 proof-reading of the manuscript. Funding was provided by the Royal Society (RG130831) to 415 the University of Portsmouth. The European Society of Biomechanics funded the mobility of 416 Valentina Danesi (ESB mobility award 2014). 


\section{References}

Aerssens, J., Boonen, S., Lowet, G., Dequeker, J., 1998. Interspecies differences in bone composition, density, and quality: potential implications for in vivo bone research. Endocrinology 139, 663-670.

Aquarius, R., Homminga, J., Hosman, A.J., Verdonschot, N., Tanck, E., 2014. Prophylactic vertebroplasty can decrease the fracture risk of adjacent vertebrae: an in vitro cadaveric study. Med Eng Phys 36, 944-948.

Bai, B., Jazrawi, L., Kummer, F., Spivak, J., 1999. The use of an injectable, biodegradable calcium phosphate bone substitute for the prophylactic augmentation of osteoporotic vertebrae and the management of vertebral compression fracture. Spine 24, $1521-1526$

Bay, B.K., Smith, T.S., Fyhrie, D.P., Saad, M., 1999. Digital Volume Correaltion: Threedimensional Strain Mapping Using X-ray Tomography. Experimental Mechanics 39, 217 226.

Belkoff, S.M., Mathis, J.M., Jasper, L.E., Deramond, H., 2001. An ex vivo biomechanical evaluation of a hydroxyapatite cement for use with vertebroplasty. Spine (Phila Pa 1976) 26, 1542-1546.

Berlemann, U., Ferguson, S.J., Nolte, L.P., Heini, P.F., 2002. Adjacent vertebral failure after vertebroplasty. A biomechanical investigation. J Bone Joint Surg Br 84, 748-752.

Bozkus, H., Crawford, N.R., Chamberlain, R.H., Valenzuela, T.D., Espinoza, A., Yuksel, Z., Dickman, C.A., 2005. Comparative anatomy of the porcine and human thoracic spines with reference to thoracoscopic surgical techniques. Surgical endoscopy 19, 1652-1665.

Brandolini, N., Cristofolini, L., Viceconti, M., 2014. Experimental methods for the biomechanical investigation of the human spine: a review Journal of Mechanics in Medicine and Biology 14, 1430002 (1430033 pages).

Brémand F., G.A., Doumalin P., Dupré J.C., 2008. Study of mechanical behavior of cancellous bone by Digital Volume Correlation and X-ray Micro-Computed Tomography In: Proceedings of the XIth International Congress and Exposition (Orlando, FL, USA).

Buffière, J.Y., Maire, E., Adrien, J., Masse, J.P., Boller, E., 2010. In Situ Experiments with $\mathrm{X}$ ray Tomography: an Attractive Tool for Experimental Mechanics. Experimental Mechanics 50, 289-295.

Campos-Lopez, J.P., Fuerte-Hernandez, A., Hernandez-Gomez, L.H., Martinez-Garcia, A., Beltran-Fernandez, J.A., Urriolagoitia-Calderon, G., 2015. Determination of the mechanical properties of lumbar porcine vertebrae with $2 \mathrm{D}$ digital image correlation. Journal of applied biomaterials \& functional materials 13, e195-200.

Carrodeguas, R.G., Lasa, B.V., Del Barrio, J.S., 2004. Injectable acrylic bone cements for vertebroplasty with improved properties. Journal of biomedical materials research. Part B, Applied biomaterials 68, 94-104.

Chiang, C.K., Wang, Y.H., Yang, C.Y., Yang, B.D., Wang, J.L., 2009. Prophylactic vertebroplasty may reduce the risk of adjacent intact vertebra from fatigue injury: an ex vivo biomechanical study. Spine (Phila Pa 1976) 34, 356-364.

Christen, D., Levchuk, A., Schori, S., Schneider, P., Boyd, S.K., Muller, R., 2012. Deformable image registration and 3D strain mapping for the quantitative assessment of cortical bone microdamage. Journal of Mechanical Behavior of Biomedical Materials 8, 184-193. 
Cristofolini, L., Brandolini, N., Danesi, V., Erani, P., Viceconti, M., Ferguson, S.J., 2016. A PRELIMINARY IN VITRO BIOMECHANICAL EVALUATION OF PROPHYLACTIC CEMENT AUGMENTATION OF THE THORACOLUMBAR VERTEBRAE. Journal of Mechanics in Medicine and Biology 16, 1650074.

Cristofolini, L., Brandolini, N., Danesi, V., Juszczyk, M.M., Erani, P., Viceconti, M., 2013. Strain distribution in the lumbar vertebrae under different loading configurations. The Spine Journal 13, 1281-1292.

Cristofolini, L., Schileo, E., Juszczyk, M., Taddei, F., Martelli, S., Viceconti, M., 2010. Mechanical testing of bones: the positive synergy of finite-element models and in vitro experiments. Philosophical transactions. Series A, Mathematical, physical, and engineering sciences 368, 2725-2763.

Dall'Ara, E., Barber, D., Viceconti, M., 2014. About the inevitable compromise between spatial resolution and accuracy of strain measurement for bone tissue: A 3D zero-strain study. J Biomech 47, 2956-2963.

Danesi, V., Zani, L., Scheele, A., Berra, F., Cristofolini, L., 2014. Reproducible reference frame for in vitro testing of the human vertebrae. Journal of biomechanics 47, 313-318.

Dean, J.R., Ison, K.T., Gishen, P., 2000. The strengthening effect of percutaneous vertebroplasty. Clinical radiology 55, 471-476.

Diamond, T.H., Champion, B., Clark, W.A., 2003. Management of acute osteoporotic vertebral fractures: a nonrandomized trial comparing percutaneous vertebroplasty with conservative therapy. The American Journal of Medicine 114, 257-265.

Ferrar, L., Jiang, G., Adams, J., Eastell, R., 2005. Identification of vertebral fractures: An update. Osteoporosis International 16, 717-728.

Freddi, A., Olmi, G., Cristofolini, L., 2015. Experimental Stress Analysis for Materials and Structures: Stress Analysis Models for Developing Design Methodologies. Springer, Cham (Switzerland).

Furtado, N., Oakland, R.J., Wilcox, R.K., Hall, R.M., 2007. A Biomechanical Investigation of Vertebroplasty in Osteoporotic Compression Fractures and in Prophylactic $\begin{array}{llll}\text { Vertebral } & \text { Reinforcement. } & \text { Spine } & 32,\end{array}$ 410.1097/BRS.1090b1013e31811ea31812ee.

Giambini, H.W., H; Nassr, A; An, K; Dragomir-Daescu, D, 2013. Surface Strain Analysis Using Digital Image Correlation in Induced Vertebral Wedge Fracture. ORS 2013 Annual Meeting.

Gillard, F., Boardman, R., Mavrogordato, M., Hollis, D., Sinclair, I., Pierron, F., Browne, M., 2014. The application of digital volume correlation (DVC) to study the microstructural behaviour of trabecular bone during compression. Journal of the mechanical behavior of biomedical materials 29, 480-499.

Goldstein, C.L., Chutkan, N.B., Choma, T.J., Orr, R.D., 2015. Management of the Elderly With Vertebral Compression Fractures. Neurosurgery 77 Suppl 4, S33-45.

Grados, F., Depriester, C., Cayrolle, G., Hardy, N., Deramond, H., Fardellone, P., 2000. Long-term observations of vertebral osteoporotic fractures treated by percutaneous vertebroplasty. Rheumatology (Oxford, England) 39, 1410-1414.

Grassi, L., Isaksson, H., 2015. Extracting accurate strain measurements in bone mechanics: A critical review of current methods. Journal of the mechanical behavior of biomedical materials 50, 43-54. 

Magnetic resonance imaging findings of subsequent fractures after vertebroplasty. Neurosurgery 64, 740-744; discussion 744-745.

Hardisty, M.R., Akens, M., Yee, A.J., Whyne, C.M., 2010. Image registration demonstrates the growth plate has a variable affect on vertebral strain. Ann Biomed Eng 38, 2948-2955.

Hardisty, M.R., Akens, M.K., Hojjat, S.P., Yee, A., Whyne, C.M., 2012. Quantification of the effect of osteolytic metastases on bone strain within whole vertebrae using image registration. J Orthop Res 30, 1032-1039.

Heini, P.F., Berlemann, U., Kaufmann, M., Lippuner, K., Fankhauser, C., van Landuyt, P., 2001. Augmentation of mechanical properties in osteoporotic vertebral bones--a biomechanical investigation of vertebroplasty efficacy with different bone cements. Eur Spine J 10, 164-171.

Henninger, H.B., Reese, S.P., Anderson, A.E., Weiss, J.A., 2010. Validation of computational models in biomechanics. Proc Inst Mech Eng H 224, 801-812.

Higgins, K.B., Harten, R.D., Langrana, N.A., Reiter, M.F., 2003. Biomechanical effects of unipedicular vertebroplasty on intact vertebrae. Spine (Phila Pa 1976) 28, 1540-1547; discussion 1548.

Hussein, A.I., Barbone, P.E., Morgan, E.F., 2012. Digital Volume Correlation for Study of the Mechanics of Whole Bones. Procedia IUTAM 4, 116-125.

Hussein, A.I., Mason, Z.D., Morgan, E.F., 2013. Presence of intervertebral discs alters observed stiffness and failure mechanisms in the vertebra. J Biomech 46, 1683-1688.

Ikeuchi, M., Yamamoto, H., Shibata, T., Otani, M., 2001. Mechanical augmentation of the vertebral body by calcium phosphate cement injection. Journal of orthopaedic science : official journal of the Japanese Orthopaedic Association 6, 39-45.

Kayanja, M.M., Ferrara, L.A., Lieberman, I.H., 2004. Distribution of anterior cortical shear strain after a thoracic wedge compression fracture. The Spine Journal 4, 76-87.

Kayanja, M.M., Togawa, D., Lieberman, I.H., 2005. Biomechanical changes after the augmentation of experimental osteoporotic vertebral compression fractures in the cadaveric thoracic spine. Spine J 5, 55-63.

Kim, S.H., Kang, H.S., Choi, J.A., Ahn, J.M., 2004. Risk factors of new compression fractures in adjacent vertebrae after percutaneous vertebroplasty. Acta radiologica (Stockholm, Sweden : 1987) 45, 440-445.

Kinzl, M., Benneker, L.M., Boger, A., Zysset, P.K., Pahr, D.H., 2012. The effect of standard and low-modulus cement augmentation on the stiffness, strength, and endplate pressure distribution in vertebroplasty. Eur Spine J 21, 920-929.

Kinzl, M., Schwiedrzik, J., Zysset, P.K., Pahr, D.H., 2013. An experimentally validated finite element method for augmented vertebral bodies. Clin Biomech (Bristol, Avon) 28, 1522.

Kobayashi, N., Numaguchi, Y., Fuwa, S., Uemura, A., Matsusako, M., Okajima, Y., Ishiyama, M., Takahashi, O., 2009. Prophylactic vertebroplasty: cement injection into nonfractured vertebral bodies during percutaneous vertebroplasty. Academic radiology 16, 136143. 
Kolb, J.P., Kueny, R.A., Puschel, K., Boger, A., Rueger, J.M., Morlock, M.M., Huber, G., Lehmann, W., 2013. Does the cement stiffness affect fatigue fracture strength of vertebrae after cement augmentation in osteoporotic patients? Eur Spine J 22, 1650-1656.

Kruger, A., Baroud, G., Noriega, D., Figiel, J., Dorschel, C., Ruchholtz, S., Oberkircher, L., 2013. Height restoration and maintenance after treating unstable osteoporotic vertebral compression fractures by cement augmentation is dependent on the cement volume used. Clin Biomech (Bristol, Avon) 28, 725-730.

Langdon, J., Way, A., Heaton, S., Bernard, J., Molloy, S., 2009. The management of spinal metastases from renal cell carcinoma. Annals of the Royal College of Surgeons of England 91, 649-652.

Lewis, G., 2006. Injectable bone cements for use in vertebroplasty and kyphoplasty: state-of-the-art review. Journal of biomedical materials research. Part B, Applied biomaterials 76, 456-468.

Lewis, G., Schwardt, J.D., Slater, T.A., Janna, S., 2008. Evaluation of a synthetic vertebral body augmentation model for rapid and reliable cyclic compression life testing of materials for balloon kyphoplasty. Journal of biomedical materials research. Part B, Applied biomaterials $87,179-188$.

Lim, T.H., Brebach, G.T., Renner, S.M., Kim, W.J., Kim, J.G., Lee, R.E., Andersson, G.B., An, H.S., 2002. Biomechanical evaluation of an injectable calcium phosphate cement for vertebroplasty. Spine (Phila Pa 1976) 27, 1297-1302.

Liu, L., Morgan, E.F., 2007. Accuracy and precision of digital volume correlation in quantifying displacements and strains in trabecular bone. J Biomech 40, 3516-3520.

Madi, K., Tozzi, G., Zhang, Q.H., Tong, J., Cossey, A., Au, A., Hollis, D., Hild, F., 2013. Computation of full-field displacements in a scaffold implant using digital volume correlation and finite element analysis. Med Eng Phys 35, 1298-1312.

Molloy, S., Riley, L.H., 3rd, Belkoff, S.M., 2005. Effect of cement volume and placement on mechanical-property restoration resulting from vertebroplasty. AJNR Am J Neuroradiol 26, 401-404.

Nazarian, A., Muller, R., 2004. Time-lapsed microstructural imaging of bone failure behavior. J Biomech 37, 55-65.

Oakland, R.J., Furtado, N.R., Wilcox, R.K., Timothy, J., Hall, R.M., 2008. The biomechanical effectiveness of prophylactic vertebroplasty: a dynamic cadaveric study. $\mathrm{J}$ Neurosurg Spine 8, 442-449.

Oakland, R.J., Furtado, N.R., Wilcox, R.K., Timothy, J., Hall, R.M., 2009. Preliminary biomechanical evaluation of prophylactic vertebral reinforcement adjacent to vertebroplasty under cyclic loading. The Spine Journal 9, 174-181.

Palanca, M., Brugo, T.M., Cristofolini, L., 2015a. Use of digital image correlation to understand the biomechanics of the vertebra. J Mech Med Biol 15:1540001-1540010.

Palanca, M., Tozzi, G., Cristofolini, L., 2016. The use of digital image correlation in the biomechanical area: a review. International Biomechanics 3.

Palanca, M., Tozzi, G., Cristofolini, L., Viceconti, M., Dall'Ara, E., 2015b. Threedimensional local measurements of bone strain and displacement: comparison of three digital volume correlation approaches. J Biomech Eng 137. 
Reece, W.O., 2004. Temperature Regulation and Thermal Environment, in Dukes' Physiology of Domestic Animals, 12th ed., Reece WO, Ed. Copyright 2004 by Cornell University.

Roberts, B.C., Perilli, E., Reynolds, K.J., 2014. Application of the digital volume correlation technique for the measurement of displacement and strain fields in bone: a literature review. J Biomech 47, 923-934.

Rotter, R., Schmitt, L., Gierer, P., Schmitz, K.P., Noriega, D., Mittlmeier, T., Meeder, P.J., Martin, H., 2015. Minimum cement volume required in vertebral body augmentation-A biomechanical study comparing the permanent SpineJack device and balloon kyphoplasty in traumatic fracture. Clin Biomech (Bristol, Avon) 30, 720-725.

Steens, J., Verdonschot, N., Aalsma, A.M., Hosman, A.J., 2007. The influence of endplate-to-endplate cement augmentation on vertebral strength and stiffness in vertebroplasty. Spine (Phila Pa 1976) 32, E419-422. Sun, K., Liebschner, M.A., 2004. Biomechanics of prophylactic vertebral reinforcement. Spine (Phila Pa 1976) 29, 1428-1435; discusssion 1435.

Sutcliffe, P., Connock, M., Shyangdan, D., Court, R., Kandala, N.B., Clarke, A., 2013. A systematic review of evidence on malignant spinal metastases: natural history and technologies for identifying patients at high risk of vertebral fracture and spinal cord compression. Health technology assessment (Winchester, England) 17, 1-274.

Tancioni, F., Lorenzetti, M.A., Navarria, P., Pessina, F., Draghi, R., Pedrazzoli, P., Scorsetti, M., Alloisio, M., Santoro, A., Rodriguez y Baena, R., 2011. Percutaneous vertebral augmentation in metastatic disease: state of the art. J Support Oncol 9, 4-10.

Tanigawa, N., Komemushi, A., Kariya, S., Kojima, H., Shomura, Y., Sawada, S., 2006. Radiological follow-up of new compression fractures following percutaneous vertebroplasty. Cardiovascular and interventional radiology 29, 92-96.

Tohmeh, A.G., Mathis, J.M., Fenton, D.C., Levine, A.M., Belkoff, S.M., 1999. Biomechanical efficacy of unipedicular versus bipedicular vertebroplasty for the management of osteoporotic compression fractures. Spine (Phila Pa 1976) 24, 1772-1776.

Tozzi, G., Danesi, V., Palanca, M., Cristofolini, L.,. Elastic full-field strain analysis and microdamage progression in the vertebral body from digital volume correlation. In press 2016 Strain.

Tozzi, G., Palanca, M., Danesi, V., Dall'Ara, E., Cristofolini, L., 2015. Strain uncertainties in digital volume correlation of natural and augmented vertebrae. 21st Congress of the European Society of Biomechanics July 5-8 2015, Prague, Czech Republic Book of abstracts, page 192.

Tozzi, G., Zhang, Q.H., Tong, J., 2012. 3D real-time micromechanical compressive behaviour of bone-cement interface: experimental and finite element studies. J Biomech 45, 356-363.

Tozzi, G., Zhang, Q.H., Tong, J., 2014. Microdamage assessment of bone-cement interfaces under monotonic and cyclic compression. J Biomech 47, 3466 - 3474.

Trout, A.T., Kallmes, D.F., Kaufmann, T.J., 2006. New fractures after vertebroplasty: adjacent fractures occur significantly sooner. AJNR Am J Neuroradiol 27, 217-223.

Uppin, A.A., Hirsch, J.A., Centenera, L.V., Pfiefer, B.A., Pazianos, A.G., Choi, I.S., 2003. Occurrence of new vertebral body fracture after percutaneous vertebroplasty in patients with osteoporosis. Radiology 226, 119-124. 
643 Widmer Soyka, R.P., Helgason, B., Hazrati Marangalou, J., van den Bergh, J.P., 644 Rietbergen, B., Ferguson, S.J., 2016. The Effectiveness of Percutaneous Vertebroplasty Is 645 Determined by the Patient-Specific Bone Condition and the Treatment Strategy. PloS one $64611, \mathrm{e} 0151680$.

Wilcox, R.K., 2006. The biomechanical effect of vertebroplasty on the adjacent vertebral body: a finite element study. Proc Inst Mech Eng H. 220, 565-572.

Wilke, H.J., Mehnert, U., Claes, L.E., Bierschneider, M.M., Jaksche, H., Boszczyk, B.M., 2006. Biomechanical evaluation of vertebroplasty and kyphoplasty with polymethyl methacrylate or calcium phosphate cement under cyclic loading. Spine (Phila Pa 1976) 31, 2934-2941.

Ye, J., Coleman, J., Hunter, M.G., Craigon, J., Campbell, K.H., Luck, M.R., 2007. Physiological temperature variants and culture media modify meiotic progression and 877-886. 


\section{CAPTIONS}

Fig. 1 - Overview of the experimental design. The vertebral bodies were dissected from the spine segments, removing all soft tissues. Prophylactic augmentation was performed on the selected specimens with two types of cements (Mendec-Spine and Calcemex-Spine). The remaining specimens were used as untreated controls as part of a different study (Tozzi et al., in press 2016). The ends of each vertebra were potted in PMMA. Destructive tests were carried out under axial-compression in a step-wise fashion. Micro-CT imaging was acquired at each loading step (0\% with $50 \mathrm{~N}$ preload, 5\%, 10\% and 15\% compression). Finally, digital volume correlation (DVC) was performed to compute the internal full-field strains.

Fig. 2 - Force-compression curves for the four specimens augmented with Mendec-Spine. The force showed a drop at the end of each step of compression: this corresponded to the stress relaxation while the specimen was allowed to settle (15 minutes), before the micro-CT scan took place (90 minutes).

Fig. 3 - Force-compression curves for the four specimens augmented with Calcemex-Spine. The force showed a drop at the end of each step of compression: this corresponded to stress relaxation while the specimen was allowed to settle (15 minutes), before the micro-CT scan took place (90 minutes).

Fig. 4 - Specimens augmented with Mendec-Spine: sagittal micro-CT slice at each compression step ("A" indicates anterior, "P" posterior). Micro-damage started to be visible at $10 \%$ compression; at the last step (15\% compression) damage became fully visible (red arrows). Conversely, no micro-damage could be observed in any specimen at the first step (5\% compression).

Fig. 5 - Specimens augmented with Calcemex-Spine: sagittal micro-CT slice at each compression step ("A" indicates anterior, "P" posterior). Micro-damage started to be visible at $10 \%$ compression; at the last step ( $15 \%$ compression) damage became fully visible (red arrows). Conversely, no micro-damage could be observed in any specimen at the first step (5\% compression). 
Fig. 6 - Specimens augmented with Mendec-Spine: Internal strain distribution for the three steps of compression. The axial component of strain (in microstrain) is shown for the 4 specimens over the same sagittal slice as in Fig. 4 (the antero-posterior and lateral-lateral components of strain are reported in the Supplementary Material). The most strained regions corresponded to the damaged region, which gradually progressed into a collapse propagating across the trabecular bone.

Fig. 7 - Specimens augmented with Calcemex-Spine: Internal strain distribution for the three steps of compression. The axial component of strain (in microstrain) is shown for the 4 specimens over the same sagittal slice as in Fig. 5 (the antero-posterior and lateral-lateral components of strain are reported in the Supplementary Material). The most strained regions corresponded to the damaged region, which gradually progressed into a collapse propagating across the trabecular bone.

Fig. 8 - Specimens augmented with Mendec-Spine: Progression of strain with compression steps $(5 \%, 10 \%$ and 15\%). The average strain (in microstrain) was computed for each transverse slice for the axial component of the DVC-computed strain maps. In general, an incremental strain pattern among the consecutive compression steps was observed in all specimens. The slices where the largest strains were observed corresponded to the regions where internal damage was localized in the vertebra (Fig. 4 and 6).

Fig. 9 - Specimens augmented with Calcemex-Spine: Progression of strain with compression steps $(5 \%, 10 \%$ and 15\%). The average strain (in microstrain) was computed for each transverse slice for the axial component of the DVC-computed strain maps. In general, an incremental strain pattern among the consecutive compression steps was observed in all specimens. The slices where the largest strains were observed corresponded to the regions where internal damage was localized in the vertebra (Fig. 5 and 7). 


\section{TABLES}

Table 1: Force experienced by the eight augmented specimens at each step of compression (absolute value). Average, standard deviation and coefficient of variation are indicated for both groups.

\begin{tabular}{cccc}
\hline Augmented Specimens & $\begin{array}{c}\text { Force at 5\% } \\
\text { compression }\end{array}$ & $\begin{array}{c}\text { Force at 10\% } \\
\text { compression }\end{array}$ & $\begin{array}{c}\text { Force at 15\% } \\
\text { compression }\end{array}$ \\
\hline Mendec-1 & $3058 \mathrm{~N}$ & $3222 \mathrm{~N}$ & $3403 \mathrm{~N}$ \\
Mendec-2 & $1502 \mathrm{~N}$ & $4125 \mathrm{~N}$ & $4064 \mathrm{~N}$ \\
Mendec-3 & $3089 \mathrm{~N}$ & $4481 \mathrm{~N}$ & $4036 \mathrm{~N}$ \\
Mendec-4 & $2532 \mathrm{~N}$ & $4267 \mathrm{~N}$ & $4053 \mathrm{~N}$ \\
Mendec: Average (SD) & $2545 \mathrm{~N}(741 \mathrm{~N})$ & $4024 \mathrm{~N}(554 \mathrm{~N})$ & $3889 \mathrm{~N}(324 \mathrm{~N})$ \\
Mendec: Coefficient of variation & $29 \%$ & $14 \%$ & $8 \%$ \\
\hline Calcemex-1 & $1101 \mathrm{~N}$ & $3007 \mathrm{~N}$ & $2057 \mathrm{~N}$ \\
Calcemex-2 & $2088 \mathrm{~N}$ & $4527 \mathrm{~N}$ & $3802 \mathrm{~N}$ \\
Calcemex-3 & $1388 \mathrm{~N}$ & $2762 \mathrm{~N}$ & $2463 \mathrm{~N}$ \\
Calcemex-4 & $2345 \mathrm{~N}$ & $3423 \mathrm{~N}$ & $3408 \mathrm{~N}$ \\
Calcemex: Average (SD) & $1731 \mathrm{~N}(583 \mathrm{~N})$ & $3430 \mathrm{~N}(781 \mathrm{~N})$ & $2933 \mathrm{~N}(810 \mathrm{~N})$ \\
Calcemex: Coefficient of variation & $34 \%$ & $23 \%$ & $28 \%$ \\
\hline
\end{tabular}


Table 2: Force experienced by the eight augmented specimens at each step of compression as a fraction of the force in the corresponding natural control vertebra (a value greater than 1.00 indicates that the augmented vertebra experienced a larger force than the control). Average, standard deviation and coefficient of variation are indicated for both groups.

\begin{tabular}{cccc}
\hline Augmented Specimens & $\begin{array}{c}\text { Force at 5\% } \\
\text { compression } \\
\text { (fraction of } \\
\text { natural control) }\end{array}$ & $\begin{array}{c}\text { Force at 10\% } \\
\text { compression } \\
\text { (fraction of } \\
\text { natural control) }\end{array}$ & $\begin{array}{c}\text { Force at 15\% } \\
\text { compression } \\
\text { (fraction of } \\
\text { natural control) }\end{array}$ \\
\hline Mendec-1 & 2.74 & 1.53 & 1.55 \\
Mendec-2 & 1.47 & 1.00 & 1.02 \\
Mendec-3 & 1.06 & 1.25 & 1.07 \\
Mendec-4 & 0.83 & Missing data for the control \\
Mendec: Average (SD) & $1.52(0.85)$ & $1.26(0.26)$ & $1.21(0.29)$ \\
Mendec: Coefficient of variation & $56 \%$ & $21 \%$ & $24 \%$ \\
\hline Calcemex-1 & 0.99 & 1.43 & 0.94 \\
Calcemex-2 & 2.04 & 1.10 & 0.95 \\
Calcemex-3 & 0.48 & 0.77 & 0.65 \\
Calcemex-4 & 0.77 & Missing data for the control \\
Calcemex: Average (SD) & $1.07(0.68)$ & $0.88(0.33)$ & $0.85(0.17)$ \\
Calcemex: Coefficient of variation & $64 \%$ & $37 \%$ & $20 \%$ \\
\hline
\end{tabular}


Fig 1

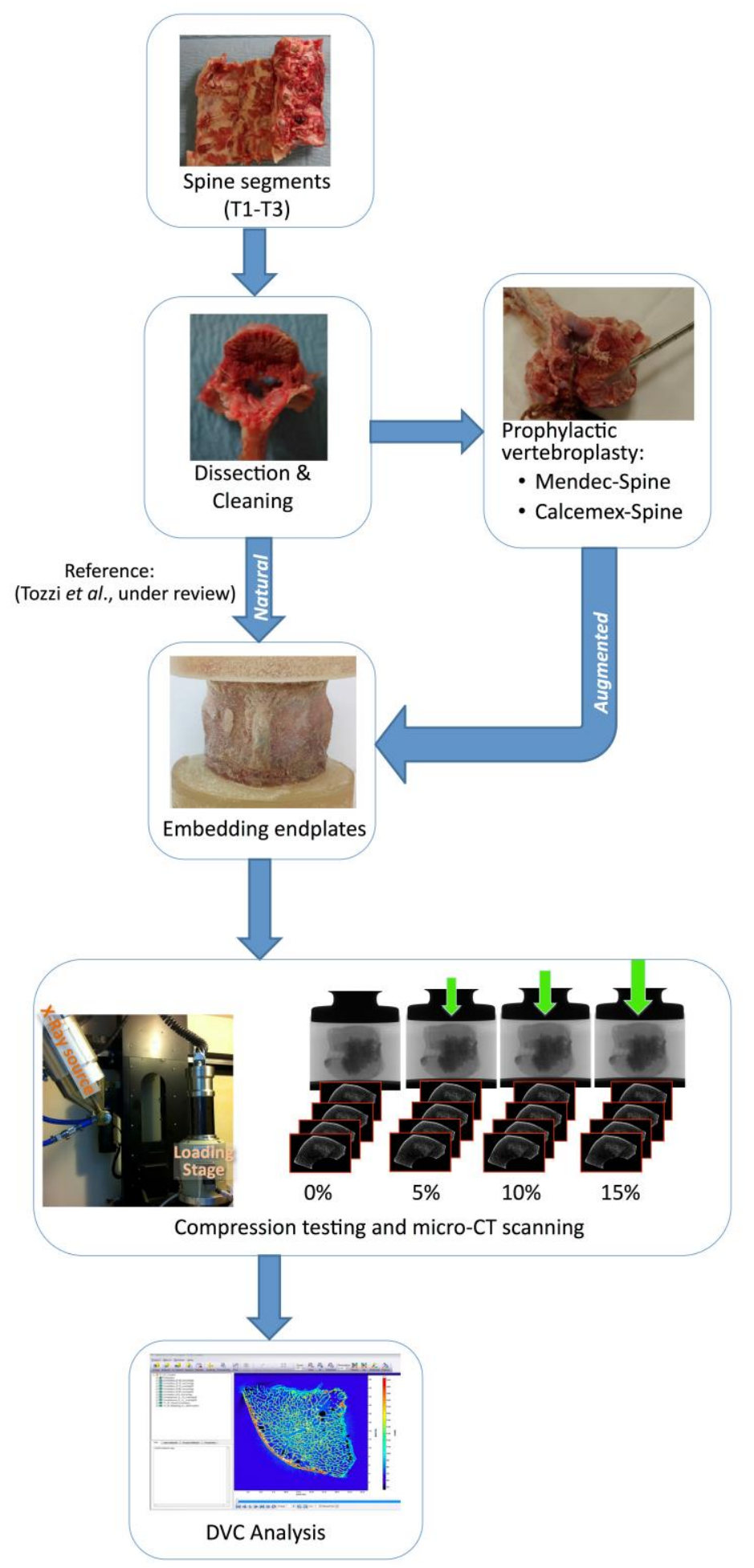




\section{Fig 2}

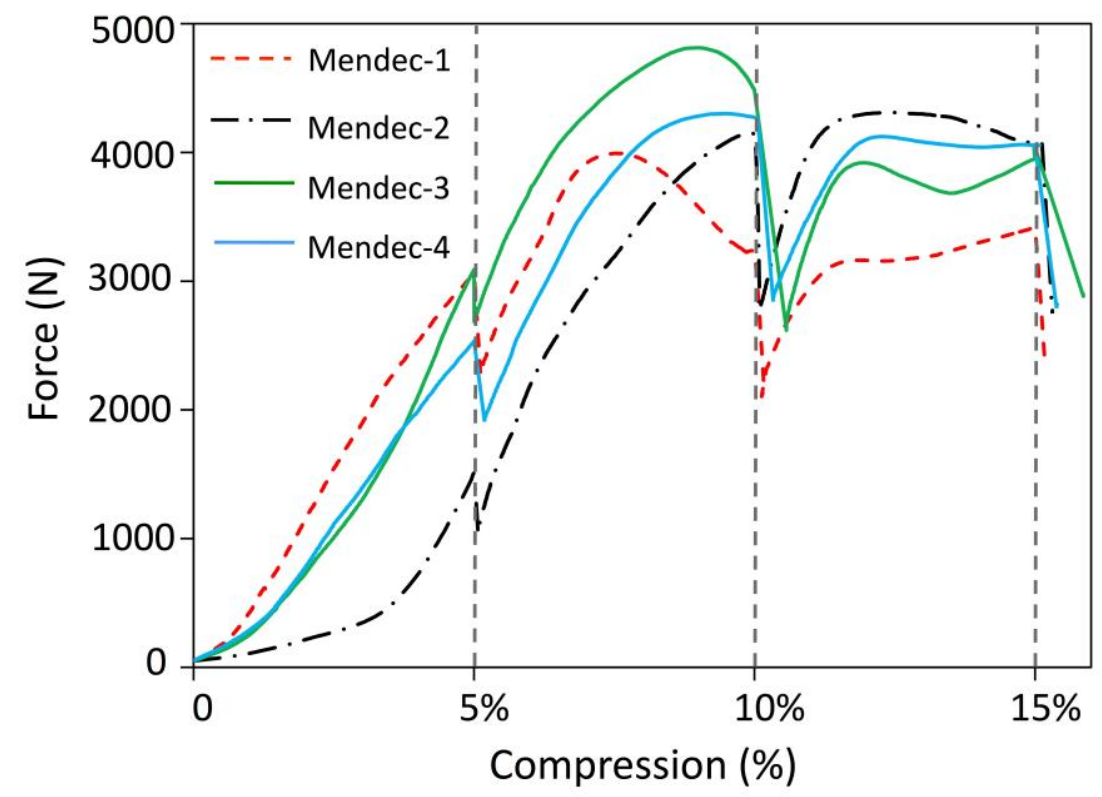

Fig 3

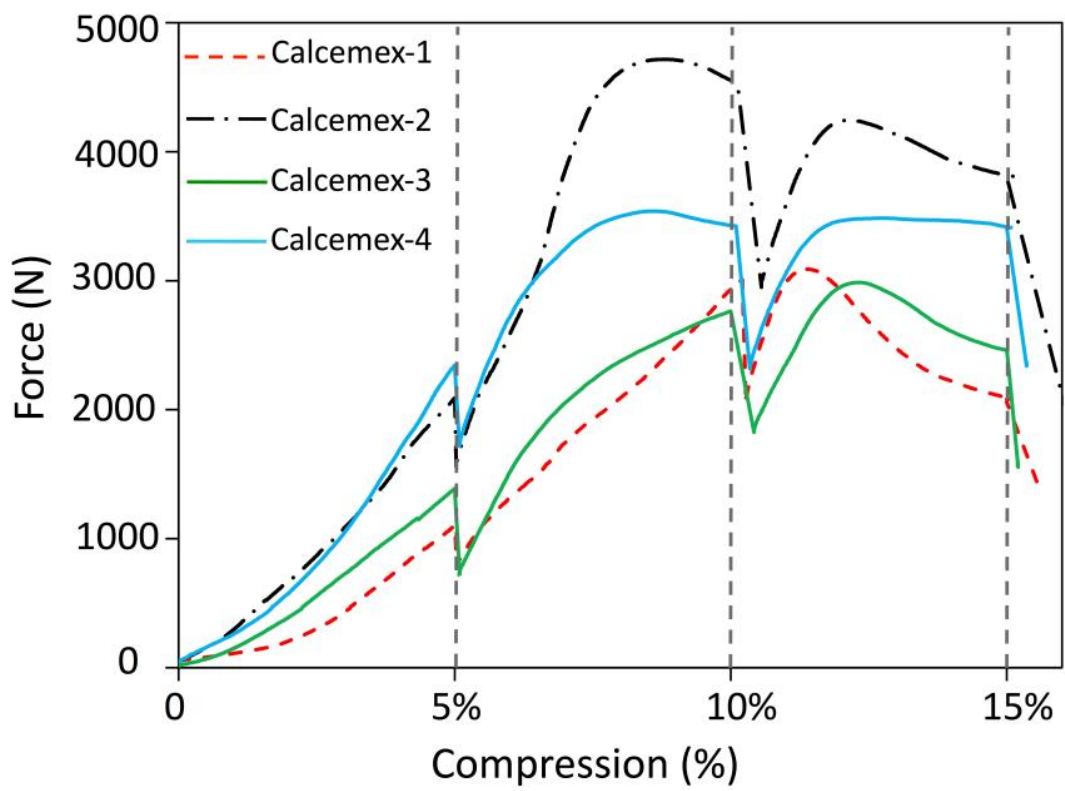


Fig 4

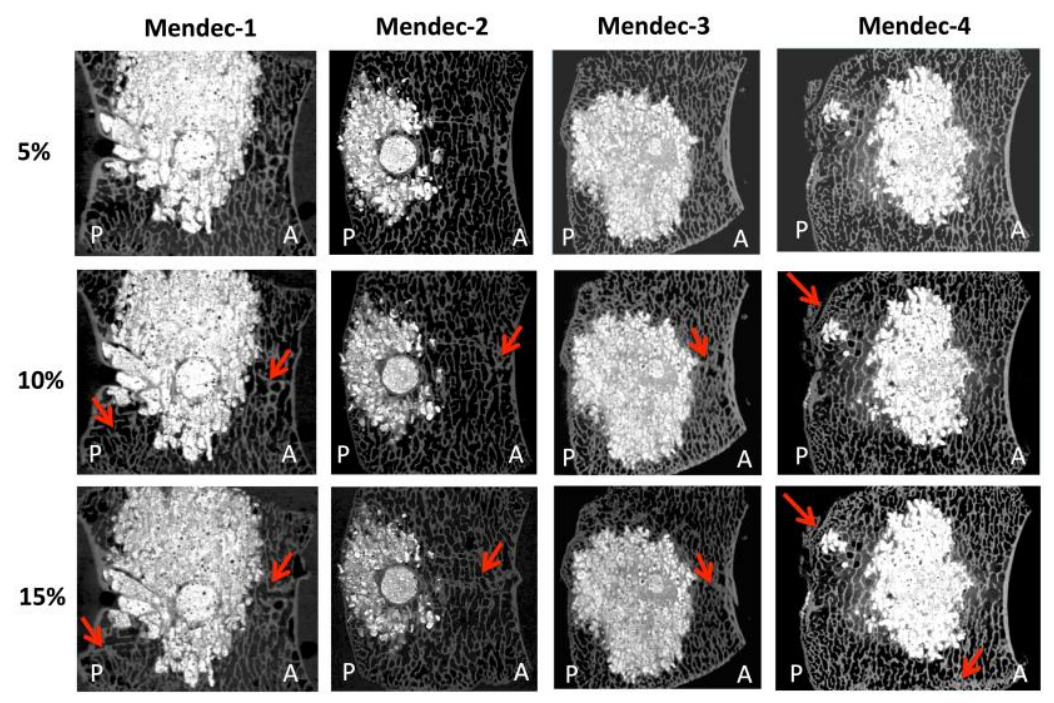

Fig 5

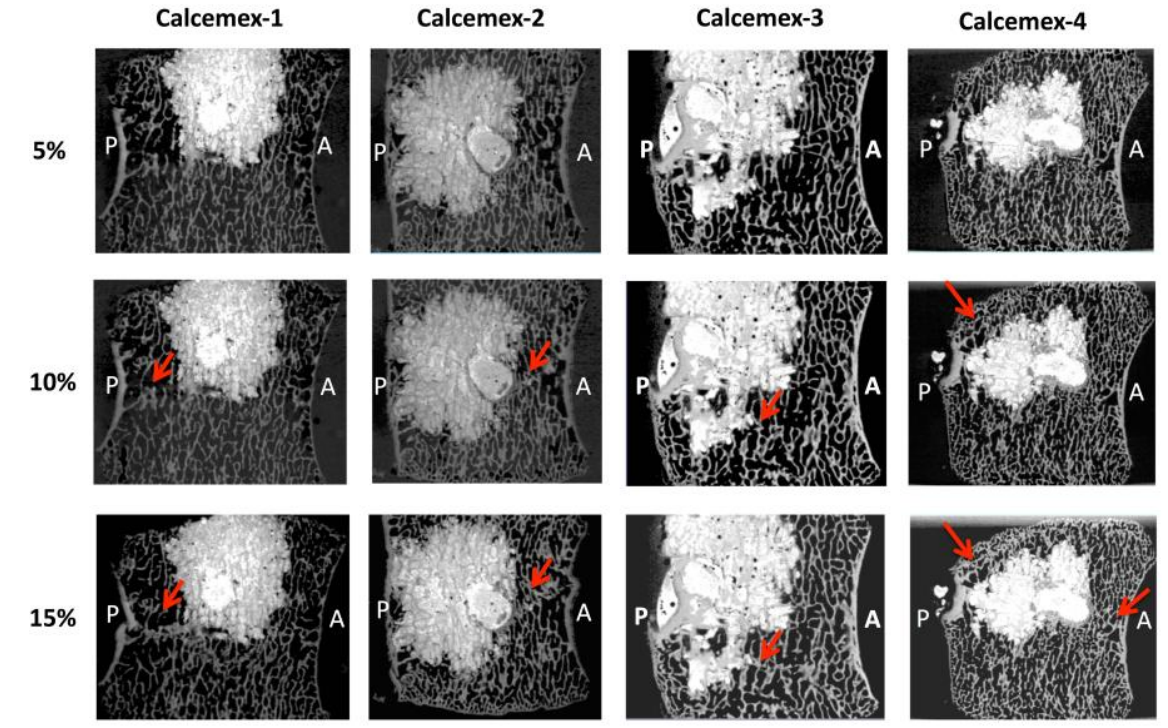


Fig 6

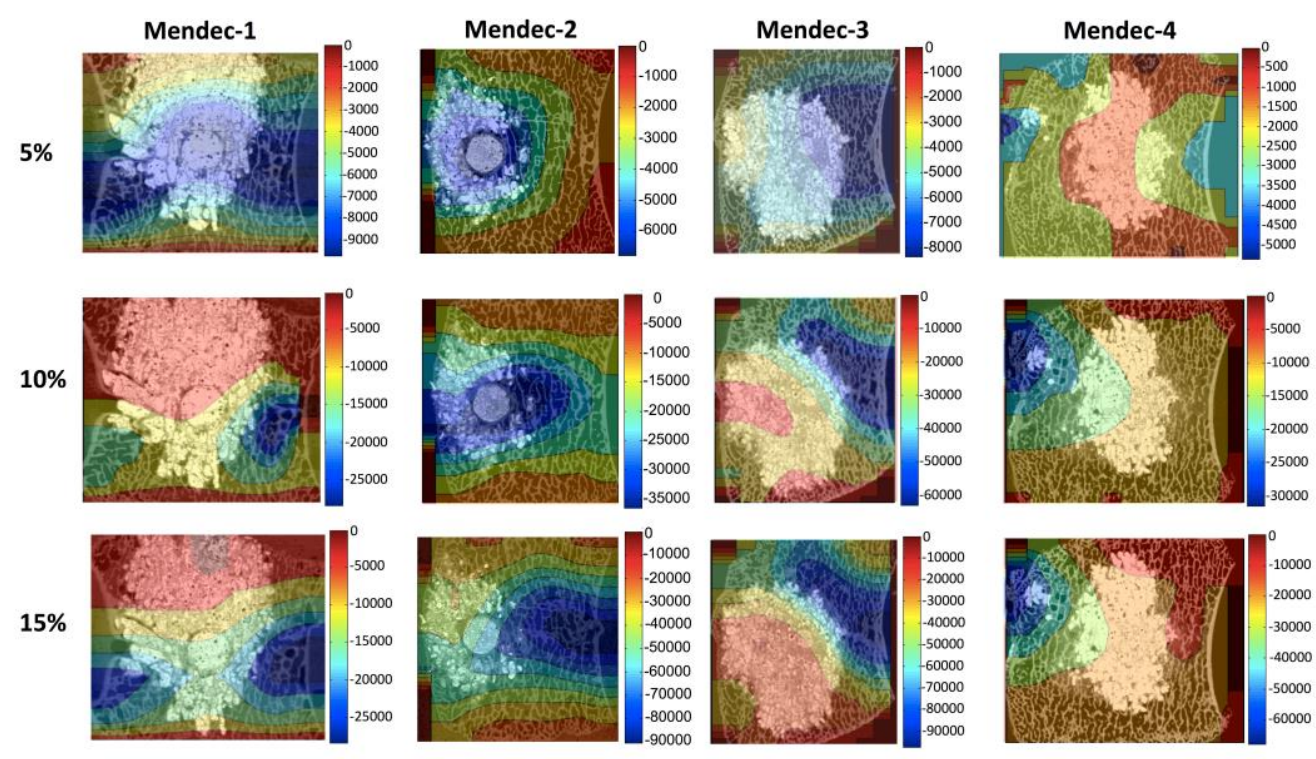

Fig 7

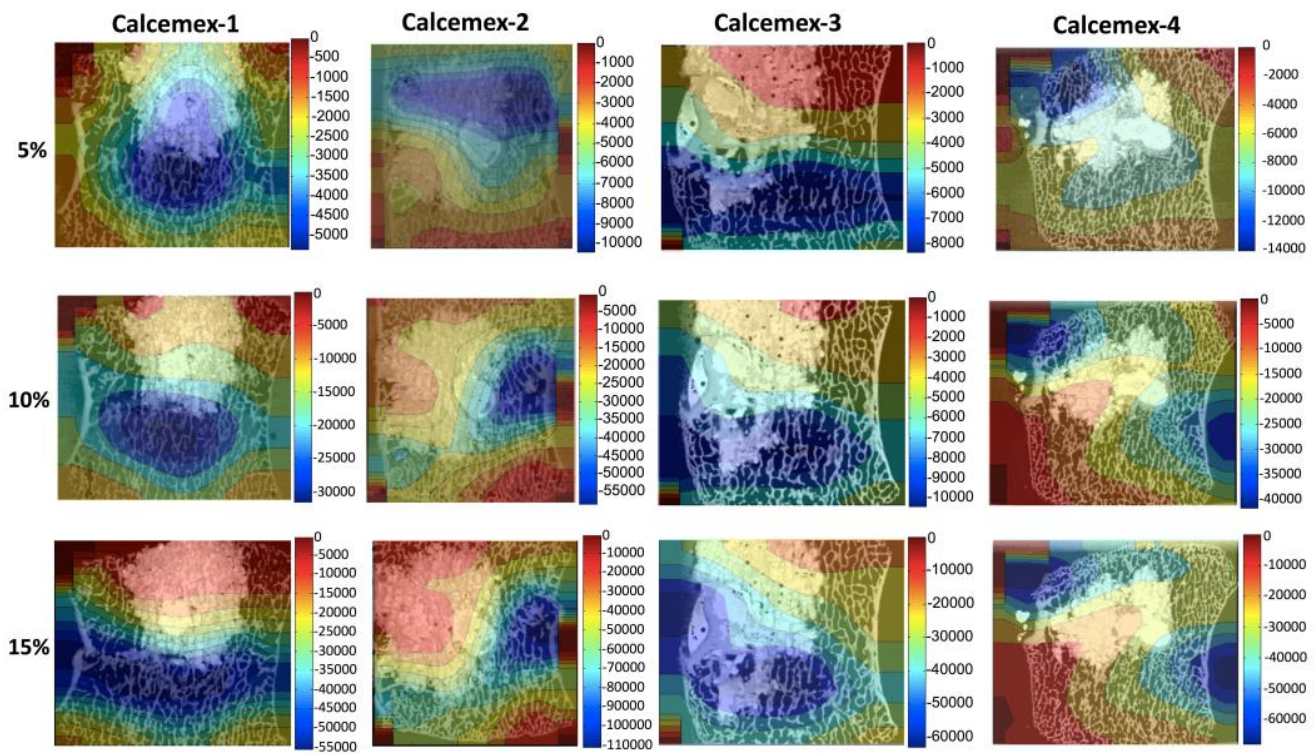


Fig 8
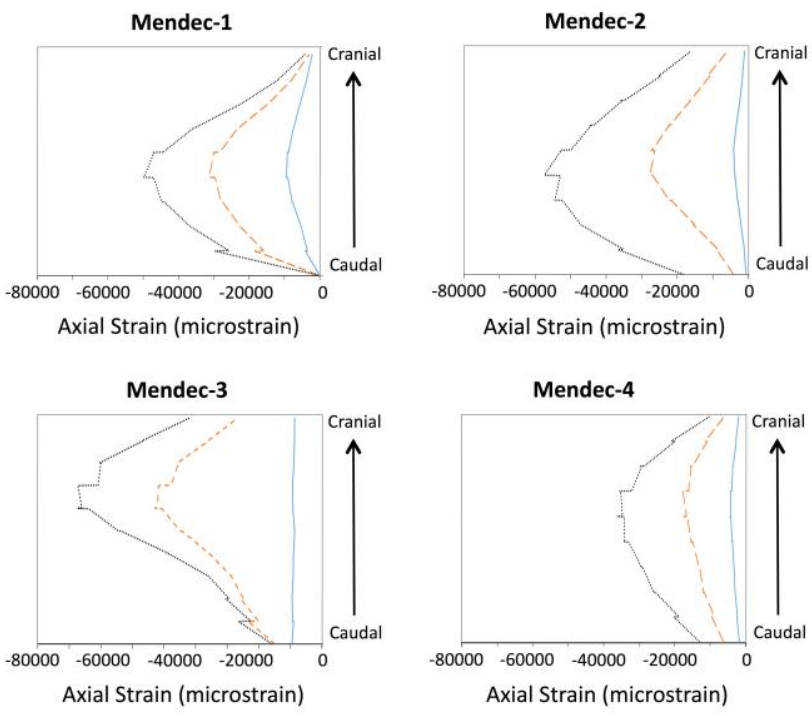

Compressive steps:
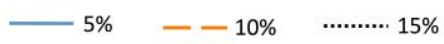

Fig 9

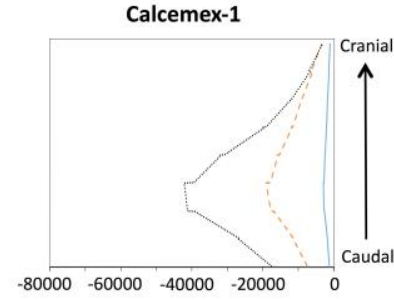

Axial Strain (microstrain)

Calcemex-3

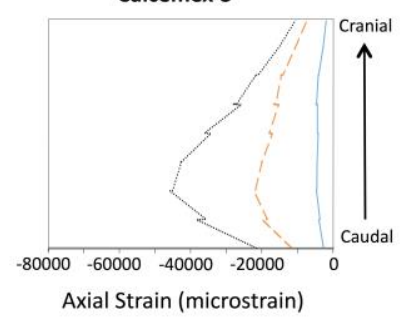

Compressive steps:

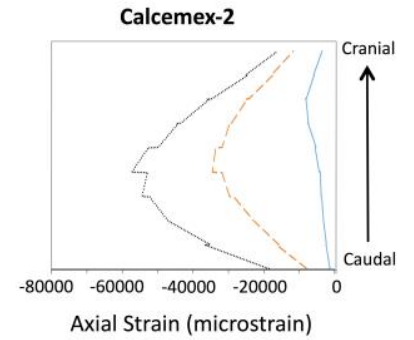

Calcemex-4

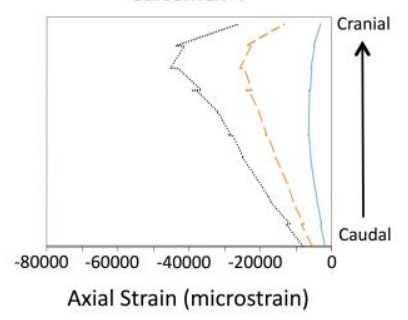

$-10 \% \quad$........... $15 \%$ 